\title{
The effect of pH on Synthsis of BiOCl and its photocatalytic oxidization performance
}

Jing Zhang ${ }^{1}$, Jiang $\mathrm{Wu}^{1 *}$, Ping $\mathrm{Lu}^{2}$, Qizhen Liu ${ }^{3}$, Tianfang Huang ${ }^{1}$, Huan Tian ${ }^{1}$, Ruixing Zhou ${ }^{1}$, Jianxing Ren ${ }^{1}$, Binxia Yuan ${ }^{1}$, Xiaoming Sun ${ }^{1}$, Wenbo Zhang ${ }^{1}$

${ }^{1}$ College of Energy and Mechanical Engineering, Shanghai University of Electric Power, Shanghai 200090, China

${ }^{2}$ School of Energy and Mechanical Engineering, Nanjing Normal University, Nanjing 210042, China

${ }^{3}$ Shanghai environment monitoring center, Shanghai 200030, China

\section{Corresponding author}

\section{Jiang WU}

Tel: $\mathbf{+ 8 6 - 2 1 - 3 5 3 0 3 9 0 2}$

Mobile: +86-13761615154

E-mail Address: wjcfd2002@sina.com

Postal Address: NO. 2103 Pingliang Road, Shanghai 200090, P. R. China.

\begin{abstract}
To explore the effect of $\mathrm{pH}$ on the photocatalytic oxidation activities of $\mathrm{BiOCl}$ catalysts, the $\mathrm{BiOCl}$ catalysts under different $\mathrm{pH}$ values were prepared via a facile hydrothermal method. The as-prepared catalysts were characterized by BET, XRD,HRSEM,SEM and UV-vis to find out the impact of $\mathrm{pH}$ values. Photocatalytic ability of $\mathrm{BiOCl}$ catalysts were evaluated by oxidation of gaseous elemental mercury under UV light irradiation. It was found that $\mathrm{BiOCl}$ catalysts prepared under alkaline condition exhibited the best photocatalytic oxidation activities. The difference of photocatalytic activity among the as-prepared catalysts can be attribute to the growth orientation of the crystal $\mathrm{BiOCl}$ catalyst and the adsorption capacity of elemental mercury.
\end{abstract}

Keywords: $\mathrm{BiOCl}$ catalyst; photocatalysis; elemental mercury; $\mathrm{pH}$ value

\section{Introduction}

Mercury has the characteristics of toxicity and persistent bioaccumulation in the environment, which is threat to human health. One of the major anthropogenic source is coal -fired flue gas from the power plant emission. There are three forms of mercury in the coal-fired flue gas: elemental mercury $\left(\mathrm{Hg}^{0}\right)$, oxidized $\mathrm{Hg}\left(\mathrm{Hg}^{2+}\right)$ and particulate $\mathrm{Hg}\left(\mathrm{Hg}_{\mathrm{p}}\right) .{ }^{1,2} \mathrm{Hg}^{2+}$ can be removed by wet scrubbers, whereas electrostatic precipitator (ESP) or fabric filter (FF) can easily remove $\mathrm{Hg}_{\mathrm{P}}$. The removal efficiency of $\mathrm{Hg}_{\mathrm{P}}$ and $\mathrm{Hg}^{2+}$ can reach up to $90 \%$. However, due to the volatility, insolubility and chemical stability, $\mathrm{Hg}^{0}$ is difficult to remove. ${ }^{3}$ 
Bismuth oxychloride is of lower valence band energy, so it has strong oxidation ability. Furthermore, bismuth oxychloride has been taken more and more attention beause of its layered structure. Its layered structure feature may promote its photocatalytic performance due to self-built internal static electric fields, which can enhance effective separation of the photoinduced electron-hole pairs. ${ }^{4-5}$ Electron-hole pairs are the important factors for photocatalytic oxidation on elemental mercury, which has been reported in our previous research ${ }^{6}$. The $\mathrm{Cl} 2 \mathrm{p}, \mathrm{O} 2 \mathrm{p}$ and $\mathrm{Bi} 6 \mathrm{~s}$ orbitals constituted valence band of $\mathrm{BiOCl}$, and the $\mathrm{Bi} 6 \mathrm{p}$ and $\mathrm{Bi}$ 6s orbitals constituted the conduction band $\left(0.308 \mathrm{~V} \mathrm{Bi}^{3+} / \mathrm{Bi} \text { vs.SHE }\right)^{7}$. The bandgap energy was estimated at approximately $3.46 \mathrm{eV}^{8-13}$, which can be excited by UV light. However, bandgap energy is not the single factor for photocatalytic oxidation on elemental mercury. As we known, $\mathrm{pH}$ could influence the size, stability and morphology of the prepared catalysts ${ }^{18}$. In order to further explore the effect of $\mathrm{pH}$ values on photocatalytic oxidation elemental mercury activity, we prepared $\mathrm{BiOCl}$ samples by using hydrothermal method under different $\mathrm{pH}$ values.

\section{Experimental methods}

\subsection{Materials and reagents}

$\mathrm{Bi}\left(\mathrm{NO}_{3}\right)_{3} \cdot 5 \mathrm{H}_{2} \mathrm{O}$ and $\mathrm{NaCl}$ were purchased from Guoyao Chemical Reagent Co. Ltd. All chemicals were analytical grade and used without further purification.

\subsection{Preparation}

The preparation of detailed process was as follows: $4 \mathrm{mmol} \mathrm{Bi}\left(\mathrm{NO}_{3}\right)_{3} \cdot 5 \mathrm{H}_{2} \mathrm{O}$ was dissolved in $48 \mathrm{ml}$ ultra-water. The suspension was stirred for $20 \mathrm{~min}$ until $\mathrm{Bi}\left(\mathrm{NO}_{3}\right)_{3} \cdot 5 \mathrm{H}_{2} \mathrm{O}$ was completely dissolved. Then, $4 \mathrm{mmol} \mathrm{NaCl}$ was dissolved in the mixture. When the solution turned into transparent, $10 \mathrm{M} \mathrm{NaOH}$ was added by drop to adjust the $\mathrm{pH}$ value of the mixture. After a further $1 \mathrm{~h}$ continuous stirring, the samples were put in $100 \mathrm{ml}$ Teflon-lined stainless steel autoclave and kept in an $160^{\circ} \mathrm{C}$ electric oven for $24 \mathrm{~h}$. When the temperature was cooled to ambient temperature, the white products were collected and washed with ultrapure water and ethanol several times and dried at $80^{\circ} \mathrm{C}$ for $12 \mathrm{~h}$. The $\mathrm{BiOCl}$ photocatalysts with different $\mathrm{pH}$ value $(2,7$ and 10$)$ were labeled BiOCl-2, BiOCl-7 and BiOCl-10 respectively.

\subsection{Characterization of Materials}

The obtained samples were characterized by X-ray diffraction (Bruker D8 Advance, Germany), FE-SEM (Phillips XL-30 FEG/NEW), HRTEM (Phillips Model CM200), UV-vis absorbance spectra (SHIMADZU UV-3600, Japan), and BET (Micromeritics ASAP 2020).

\subsection{Photocatalytic Tests}

A bench-scale experimental system was shown in the Fig.1(a) to evaluate the catalytic activities, which was similar to that used in our previous study ${ }^{6}$. Briefly, $\mathrm{N}_{2}$ stream with a flow rate of $0.2 \mathrm{Lmin}^{-1}$ passed through mercury generating device ( PSA 10.525 SIR GALAHAD II, UK) to introduce $\mathrm{Hg}^{0}$ vapor into photocatalytic reaction system. The reactor was flat-plate shape, which was consisted of hollow stainless steel square cell and a quartz glass used as a lid. Catalysts were loaded on a rectangular glass plate, and put into the cavity of the photocatalytic reactor, shown as Fig.1(b). The $\mathrm{Hg}^{0}$ inlet concentration was controlled around $55 \mu \mathrm{gm}^{-3}$. UV lamp ( $254 \mathrm{~nm}$ ) was fixed right on the top of reactor at the $5 \mathrm{~cm}$ height. An on-line mercury analyzer (VM-3000 Mercury Vapor Monitor, Mercury Instruments, Germany) was applied to detect the gas 
phase concentration of $\mathrm{Hg}^{0}$ based on atomic absorption spectrometry.

$\mathrm{Hg}^{0}$ removal efficiency $(\eta)$ over can be defined using eq. 1 .

$$
\eta=\frac{H g^{0}{ }_{\text {in }}-H g^{0}{ }_{\text {out }}}{H g^{0}{ }_{\text {in }}} \times 100 \%
$$

where $\mathrm{Hg}_{\text {in }}^{0}$ and $\mathrm{Hg}_{\text {out }}^{0}$ represented the concentration of $\mathrm{Hg}^{0}$ at the inlet and outlet of the photocatalytic reactor, respectively.

\section{Results and discussions}

Fig.1(c) showed the XRD patterns of $\mathrm{BiOCl}$ photocatalysts in the $2 \theta$ range $10^{\circ}-70^{\circ}$. The diffraction peaks of XRD patterns were in accordance with tetragonal BiOCl (PDF \#06-0249) perfectly. The main X-ray diffraction peaks of $\mathrm{BiOCl}$ located at $2 \theta=11.97^{\circ}, 24.03^{\circ}, 25.90^{\circ}, 32.46^{\circ}$ and $33.48^{\circ}$ corresponded to the planes of (001), (002), (101), (110) and (102) respectively. The sharp diffraction peaks indicated the as-prepared samples were the perfect crystalline phase. However, the intensities of dominated diffraction peaks of different $\mathrm{BiOCl}$ photocatalysts were various. The intensity ratios of (002/101) diffraction peak for BiOCl-2, BiOCl-7 and BiOCl-10 were $0.46,1.24$ and 0.19 respectively. The standard value was 0.16 . When the $\mathrm{pH}$ value equaled to 10 , the intensity ratios of (002/101) diffraction peak were close to standard value. At the $\mathrm{pH}$ value equaled to 2 and 7, the intensity ratios of (002/101) diffraction peak were much higher than standard value, which indicated that the dominated diffraction peaks of BiOCl-7 was (002). Under different $\mathrm{pH}$ value, the growth direction of $\mathrm{BiOCl}$ was different. Under alkaline condition, the growth direction of $\mathrm{BiOCl}$ was similar to that of standard $\mathrm{BiOCl}$.

SEM and HRTEM analysis were conducted to observe the morphology of photocatalysts under different $\mathrm{pH}$ value conditions and the results were shown in the Fig.2. The morphologies of photocatalysts all were regular and nanosheets, and the surfaces of the three photocatalysts were extremely smooth. Basically, pores were barely observed on the surface of the $\mathrm{BiOCl}$ photocatalysts. As we can see(Fig.2a), the shape of BiOCl-2 photocatalysts were round. There were no obvious morphology difference between the BiOCl-7 and BiOCl-10 photocatalysts (Fig.2b and c). Both shapes were rectangle nanosheets. Their average thickness were very small at around 70nm, which was a third of the BiOCl-2 thickness. The different morphologies under acidic condition indicated that excessive $\mathrm{H}^{+}$effected the mechanism of crystal growth, such as growing orientation, which agreed with the different intensity ratios of XRD patterns. For the further demonstration of $\mathrm{BiOCl}$, high-resolution HRTEM image was conducted and the results were shown in Fig. 2(d). The lattice fringes were clearly observed in HRTEM image. The interplane space of $0.275 \mathrm{~nm}$ was corresponding to (110) plane of $\mathrm{BiOCl}$ and the interplane space of $0.375 \mathrm{~nm}$ was corresponding to (110) plane ${ }^{14}$.

The optical properties of all photocatalysts were characterized by UV-vis diffuse reflectance spectroscopy. The Fig. 3(a) showed the absorption spectra of different $\mathrm{BiOCl}$ at the wavelength ranging from $200 \mathrm{~nm}$ to $800 \mathrm{~nm}$. As we can see, all absorption spectra showed similar adsorption intensity at the wavelength range under $350 \mathrm{~nm}$. The absorption spectrum of BiOCl-2 existed a 
small red shift compared to the absorption spectra of BiOCl-7, BiOCl-10.

To explore the physical properties, nitrogen adsorption-desorption measurement was conducted and the data were displayed in Table 1. As we can see, the BET surface area and pore volume of $\mathrm{BiOCl}$ were very small under acidic condition. The BET surface area and pore volume of $\mathrm{BiOCl}$ were similar under neutral and alkaline condition.

The efficiency of photocatalytic oxidation on gaseous $\mathrm{Hg}^{0}$ under UV light irradiation was shown in Fig. 3(b). As we can see, the most effective catalyst was BiOCl under alkaline condition. Its efficiency of photocatalytic oxidation on gaseous $\mathrm{Hg}^{0}$ reached up to $60 \%$. Since we have already explore the effect of $\mathrm{pH}$ on the band gap of $\mathrm{BiOCl}$ and observed a neglect difference, we can confirm that the bandgap was not the reason of the enhancement on the efficiency of photocatalytic oxidation mercury. The main difference of $\mathrm{BiOCl}$ under different condition was BET surface area and pore volume.

A larger BET surface area and pore volume led to more exposed active sites and residence time of gaseous $\mathrm{Hg}^{0}$ on catalyst surface, which was helpful to photocatalytic oxidation reaction. This can explain the low efficiency of BiOCl under acidic condition. However, both BET surface area and pore volume were similar under neutral and alkaline condition. So the different efficiency of photocatalytic oxidation on gaseous $\mathrm{Hg}^{0}$ under neutral and alkaline condition may be contribute to the different growth direction. Since, the dominant diffraction peak of BiOCl-7 was (002) and the dominated diffraction peak of BiOCl-7 was (101), we can make the conclusion that exposed (002) facet limited the photocatalytic oxidation reactions, which was clarified in our previous research $^{6}$

\section{Conclusions}

In this paper, we synthesis $\mathrm{BiOCl}$ by hydrothermal method under different $\mathrm{pH}$ value and explore the effect of $\mathrm{pH}$ on its photocatalytic oxidization performance. The efficiency of photocatalytic mercury was increased as the $\mathrm{pH}$ increased. Firstly, BET surface area and pore volume were very small under acidic condition which limited the exposed active sites and residence time of gaseous $\mathrm{Hg}^{0}$ on catalyst surface. Secondly, dominant diffraction peak of BiOCl under neutral condition. The dominated diffraction peak of $\mathrm{BiOCl}$ under neutral alkaline was (101), we can make the conclusion that exposed (002) facet limited the photocatalytic oxidation reactions.

\section{Acknowledgements}

This work was partially sponsored by NSF (Natural Science Foundation, 21237003, 50806041, 51106133, 51606115), and Shanghai Science and Technology Development (15dz1200703, $11 \mathrm{dz} 1203402,15110501000)$. 


\section{References}

[1] M.Muntean; Greet Janssens-Maenhout; S.J. Song; Noelle E. Selin; Jos G.J.Olivier; Diego Guizzardi; Rob Maas; Frank Dentener. Science of the Total Environment, 2014,494-495,337-350

[2] Constance L. Senior; Adel F. Sarofim; T.F. Zeng; Joseph J. Helble; Ruben Mamani-Paco.Fuel Processing Technology, 2000,63 197-213

[3] Y. Hao; S.M. Wu; Y. Pan; Q. Li; J.Z. Zhou;Y.B. Xu; G.R. Qian.Fuel. 2016,177,157-163

[4] J. Jiang; X. Zhang; P. B. Sun; L. Z. Zhang.J. Phys. Chem. C, 2011, 115, 20555-20564.

[5] K. L. Zhang, C. M. Liu, F. Q. Huang, C. Zheng and W. D. Wang, Appl. Catal. B, 2006, 68, $125-129$

[6] J.Wu; C.E. Li; X.Y. Zhao; Q. Wu; X.M. Qi; X.T. Chen; T. Hu; Y. Cao.Applied Catalysis B: Environmental .2015,176,559-569

[7] W.L.Huang; Q.S. Zhu. J. Comput. Chem. 2009,30, 183-190

[8] K.L. Zhang; C.M. Liu; F.Q Huang; C. Zheng; W.D. Wang. Appl. Catal. B-Environ. 2006,68, $125-129$.

[9] B. Sarwan; B. Pare; A.D. Acharya; S.B. Jonnalagadda; J. Photochem. Photobiol. B:Biol. 2012,116,48-55.

[10] Y. Tian; C.F. Guo; Y.J. Guo; Q. Wang; Q. Liu. Appl. Surf. Sci. 2012,258,1949-1954.

[11] J. Jiang; K. Zhao; X.Y. Xiao; L.Z. Zhang; J. Am. Chem. Soc.2012,134,4473-4476.

[12] J.Y. Xiong; G. Cheng; F. Qin; R.M. Wang; H.Z. Sun; R. Chen; Chem. Eng. J.2013, $220,228-236$

[13] X.C. Zhang; X.X. Liu; C.M. Fan; Y.W. Wang; Y.F. Wang;Z.H. Liang. Appl. Catal. B:Environ. 2013,132-133,332-341.

[14] G. Snider;P. Ariya, Chem.Phys. Lett. 2012,491,23-28.

[15] S.G. Botta; D.J. Rodrı' 1guez; A.G. Leyva; M.I. Litter. Catal.Today, 2002, 76, 247-258.

[16] M.S. Gustin; S.E. Lindberg; P.J. Weisberg. Appl. Geochem. 2008, 23,482-493.

[17] T. Montini;V. Gombac;L. Sordelli; J.J. Delgado;X.Chen;G.Adami;P.Fornasiero. ChemCatChem,2011, 3,574-577

[18] Chang Sung Lim; Jeong Ho Ryu;Do-Hwan Kim; Sung-Yong Cho;Won-Chun Oh.Journal of Ceramic Processing Research.2010,11,(6),736-741 


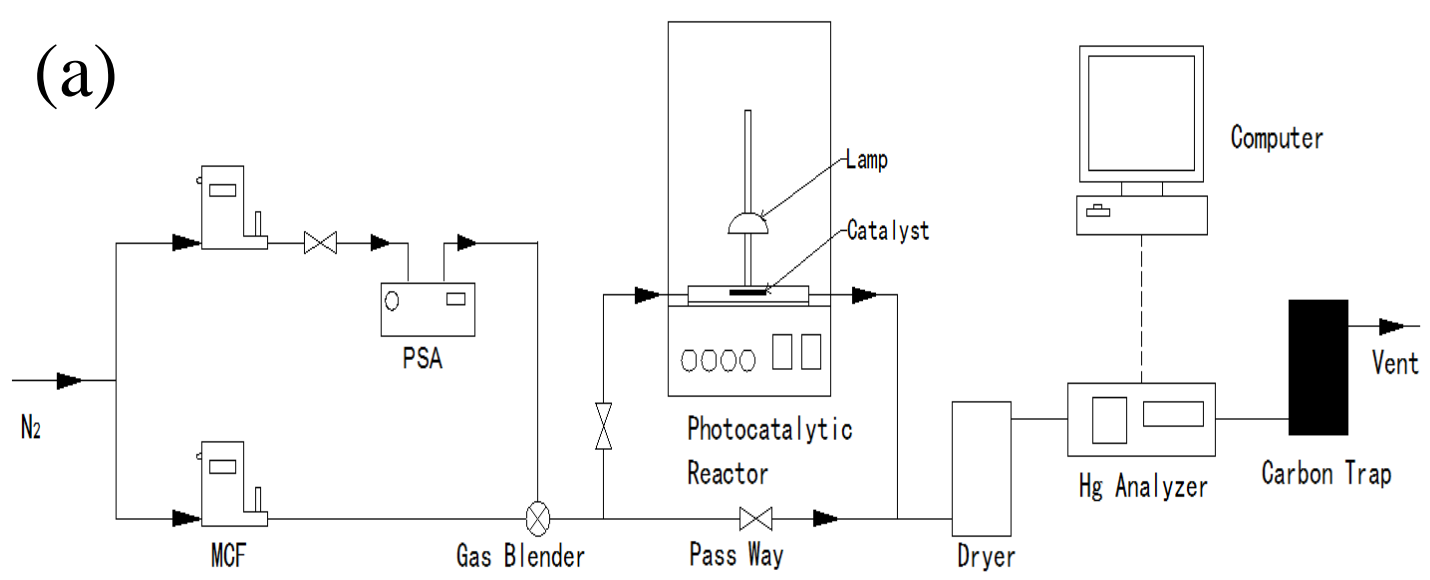

(b)

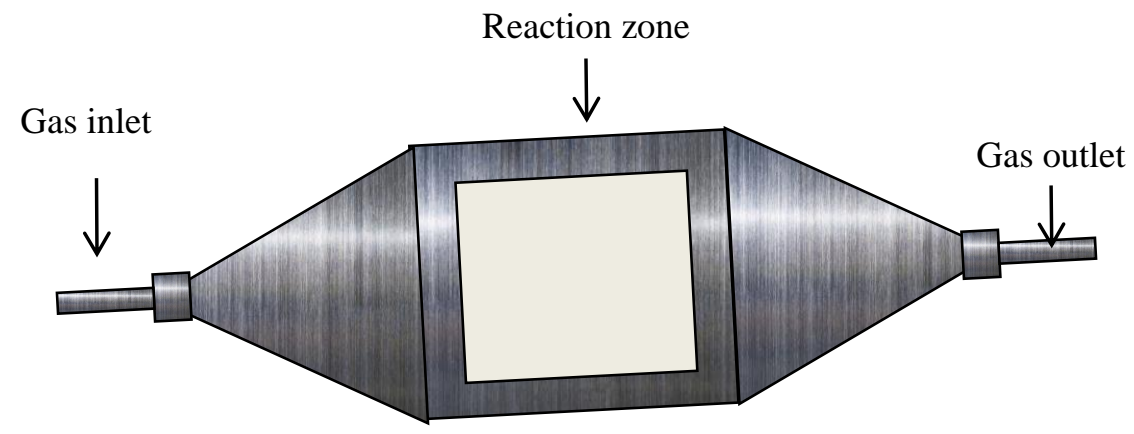

(c)

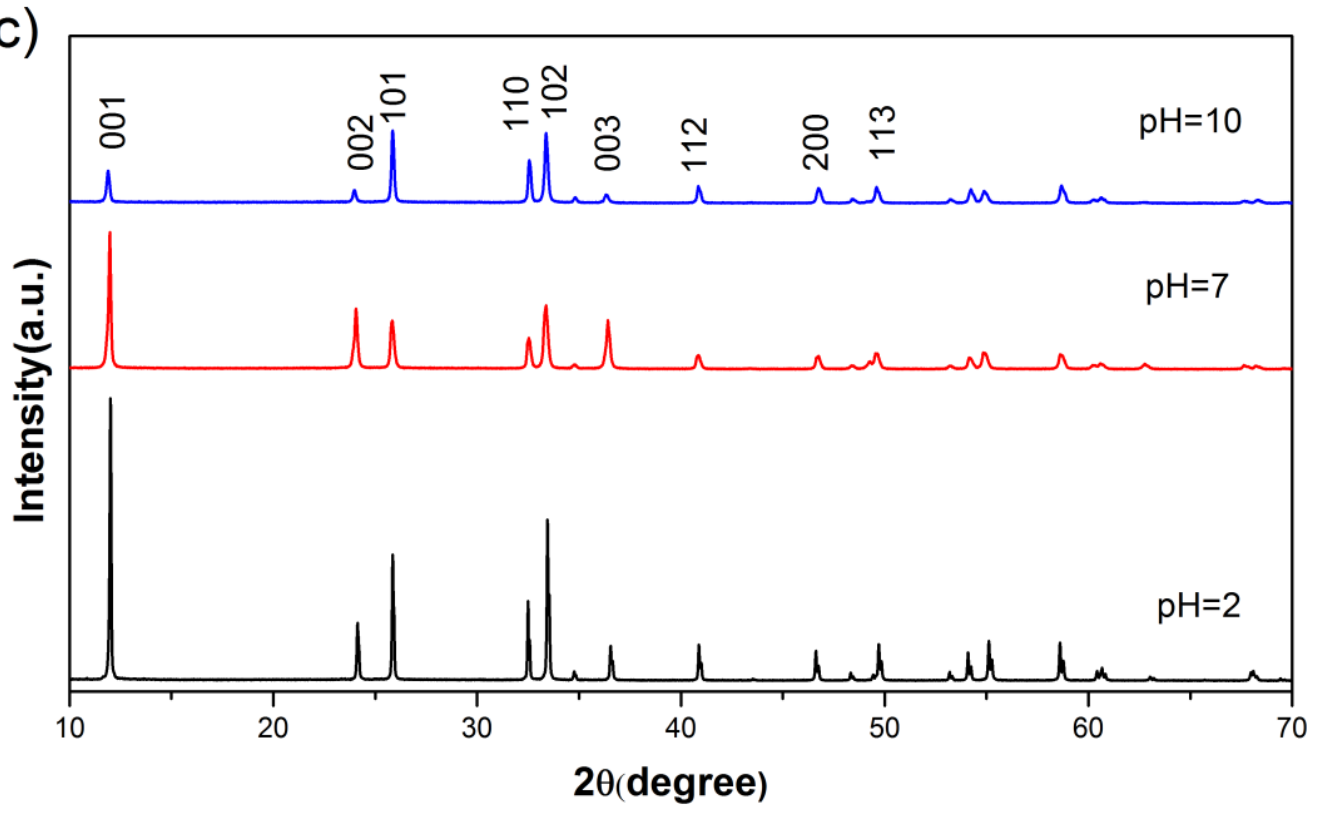

Fig.1 (a) Schematic diagram of the experimental system; (b) Schematic diagram of the the photocatalytic reactor; (c) XRD patterns for BiOCl photocatalysts 

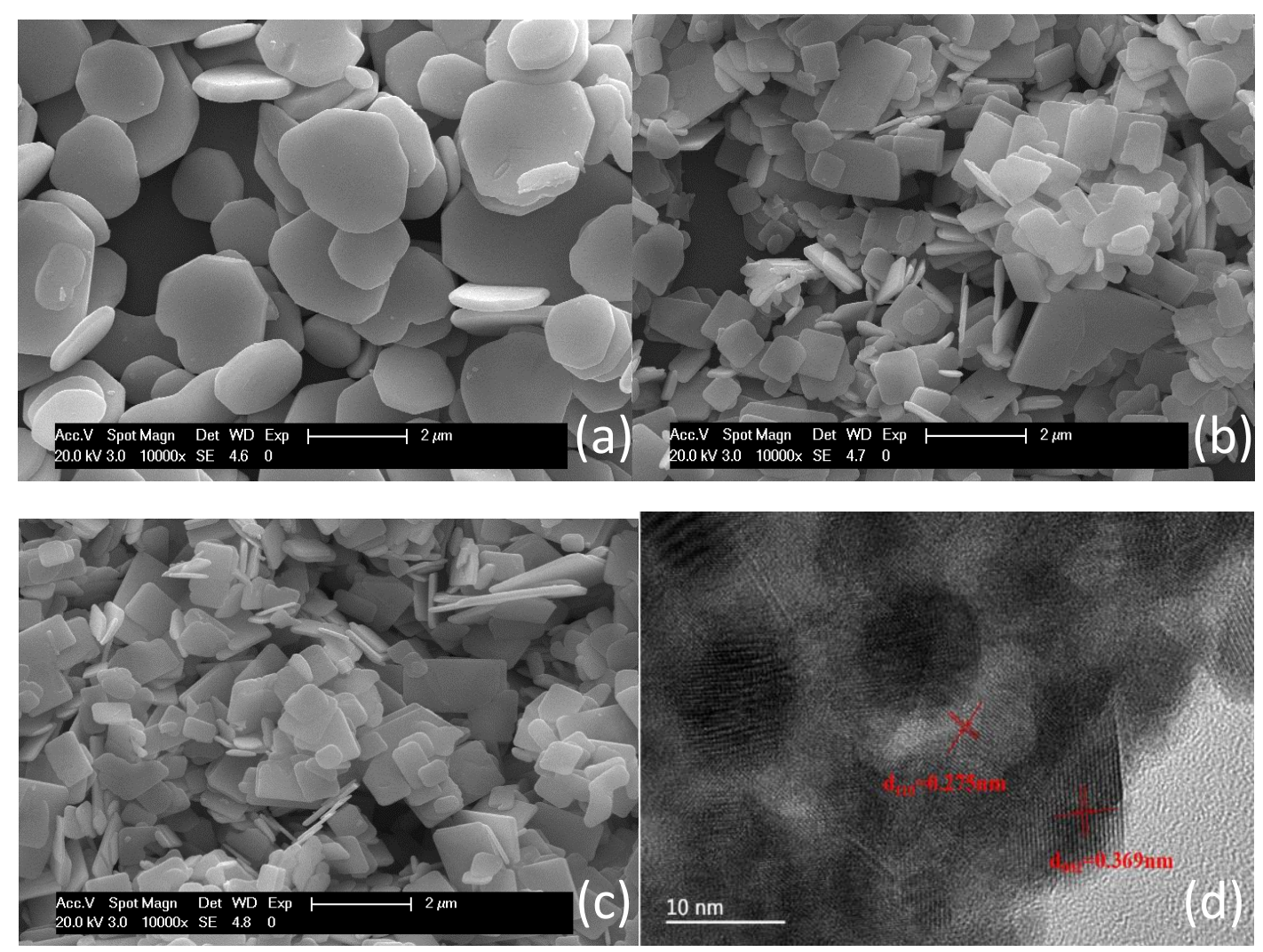

Fig.2 SEM images of (a)BiOCl-2; (b)BiOCl-7; (c)BiOCl-10; and (d)HRTEM image of $\mathrm{BiOCl}-10$ 


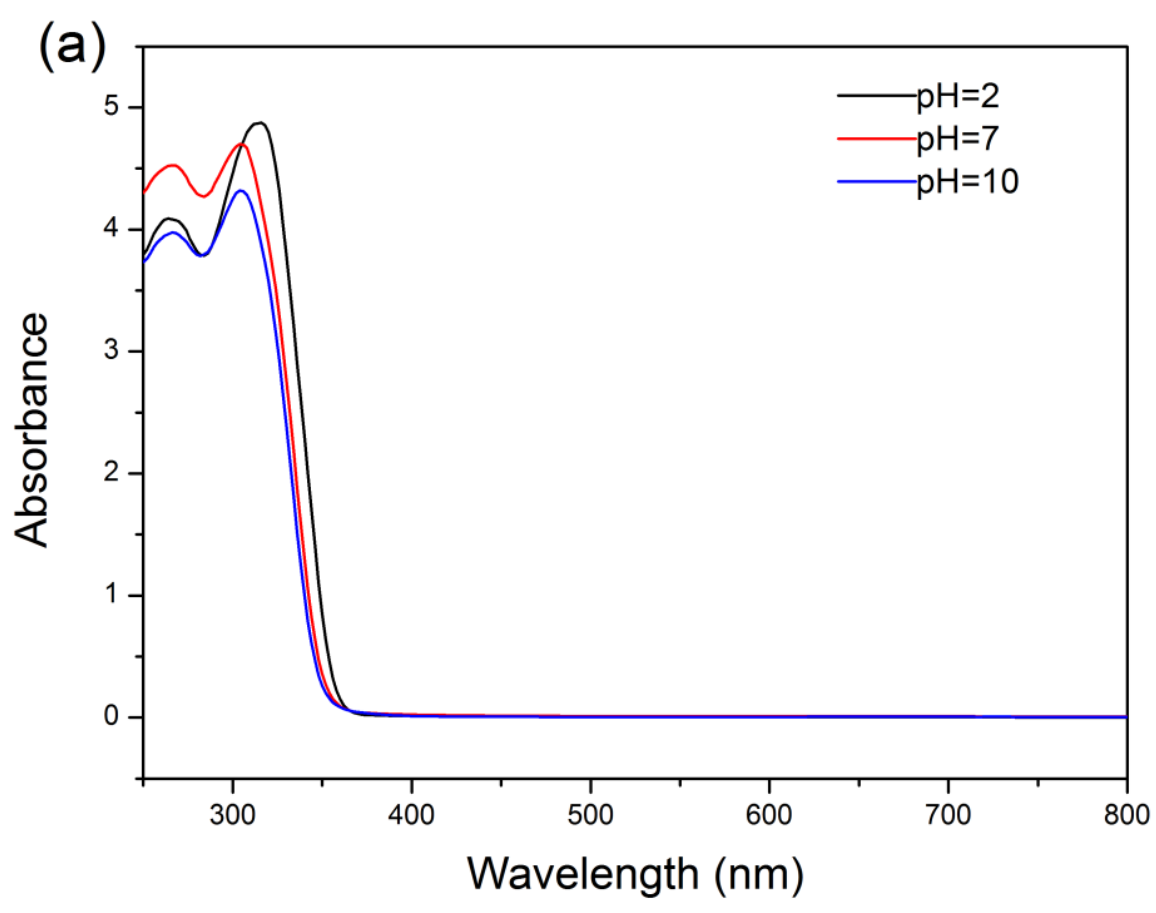

(b)

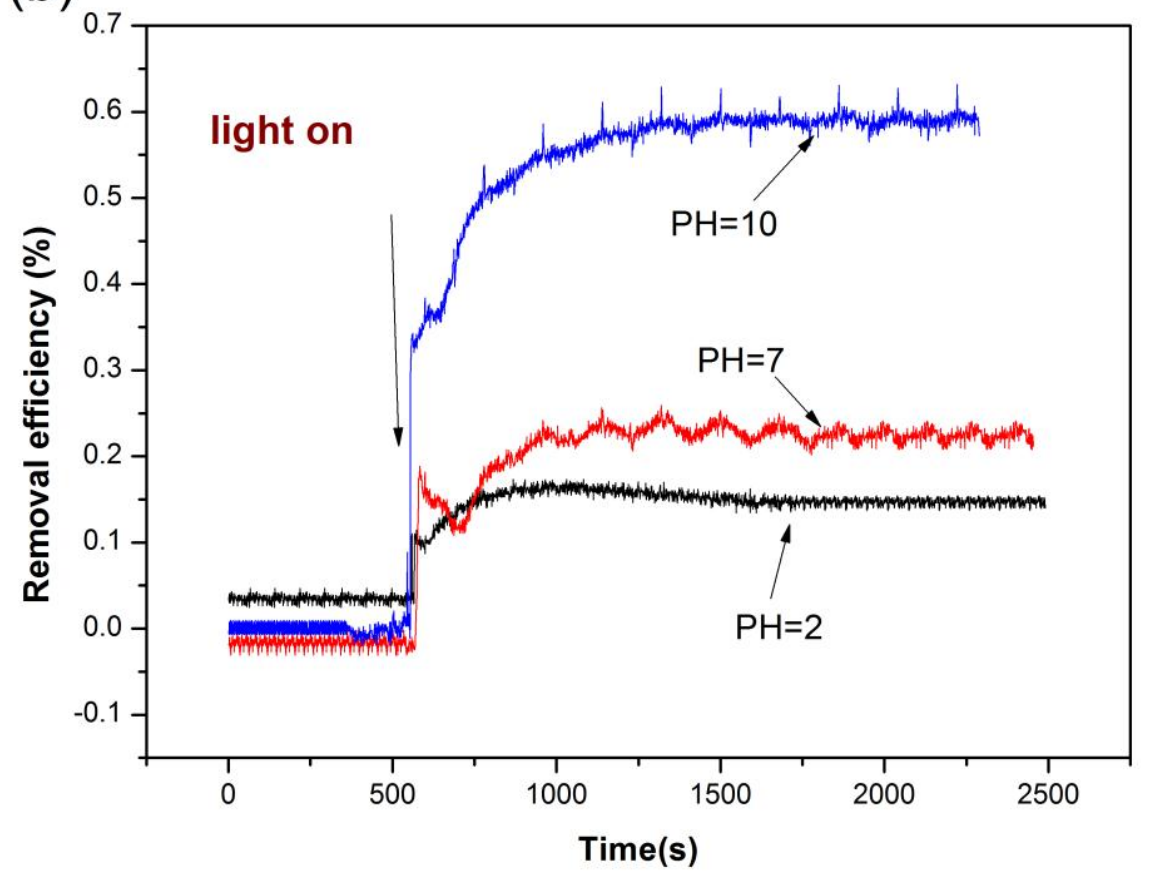

Fig. 3 (a) UV-vis absorbance spectra of $\mathrm{BiOCl}$ photocatalysts;

(b) efficiency of photocatalytic oxidation gaseous $\mathrm{Hg}^{0}$ under UV light irradiation 
Tabel 1. Physicochemical properties of BiOCl-2, BiOCl-7, BiOCl-10

\begin{tabular}{|c|c|c|c|c|}
\hline Samples & $\mathrm{E}_{\mathrm{g}}(\mathrm{eV})$ & $\begin{array}{c}\mathrm{S}_{\mathrm{BET}}{ }^{\mathrm{a}} \\
\left(\mathrm{cm}^{-2} \cdot \mathrm{g}^{-1}\right)\end{array}$ & $\mathrm{V}_{\mathrm{t}}^{\mathrm{b}}\left(\mathrm{cm}^{-3} \cdot \mathrm{g}^{-1}\right)$ & $\begin{array}{c}\mathrm{D}_{\mathrm{BJH}}{ }^{\mathrm{c}} \\
(\mathrm{nm})\end{array}$ \\
\hline BiOCl-2 & 3.46 & 0.31 & 0.002 & 21.3 \\
BiOCl-7 & 3.52 & 3.40 & 0.014 & 16.1 \\
BiOCl-10 & 3.54 & 3.02 & 0.013 & 17.17 \\
\hline
\end{tabular}

a $\mathrm{S}_{\mathrm{BET}}$, BET surface area calculated by the adsorption branch of $\mathrm{N}_{2}$ isotherm.

b $\mathrm{V}_{\mathrm{t}}$, pore volume.

c $\mathrm{D}_{\text {ВJH }}$, pore diameter determined by BJH model. 